\title{
Experimental Slip Distribution in Lentils as an Analog for Scaly Clay Fabrics
}

\author{
Matthew S. Tarling ${ }^{\mathrm{a}}$, Christie D. Rowe ${ }^{\mathrm{a}}$ \\ ${ }^{a}$ Department of Earth 83 Planetary Sciences, McGill University, 3450 University St., \\ Montréal, QC H3A 0E8, Canada
}

\begin{abstract}
Scaly fabrics are networks of anastomosing shear surfaces which are ubiquitous in deformed clay-rich sediments and fault gouges. Despite common occurrence, very little is known about their behavior during deformation. It is not known whether they represent incremental slip on individual wavy shear surfaces, or whether the anastomosing shear surfaces deform simultaneously across the network of scaly fabric.

We performed shear experiments on scaly fabric analog materials (oriented lentils) to observe the distribution of slip surfaces during deformation using a transparent 'sandbox'-type apparatus. We find that shear distributes through a network of transiently active surfaces that continually re-organize during slip. This is accompanied by local compaction and dilation so that volume changes associated with slip are balanced laterally between sub-parallel slip surfaces. The overall behavior is one in which slip is shared between subparallel slip surfaces throughout the network through time, by trading off between short, intersecting slip surfaces. The self-perpetuating delocalization behavior of the system serves as a model for conceptual understanding of how scaly fabrics deform and persist in natural clay-rich sediments and
\end{abstract}


fault gouges.

\section{Introduction}

'Scaly fabrics', also known as phacoidal cleavage, form in clay-rich rocks and sediments in a variety of deformation environments, including tectonic faults, landslides, and subglacial till (e.g. Denis et al., 2010; Dilek et al., 2012; Larue and Hudleston, 1987; Vannucchi et al., 2003). Their prevalence in the matrix of tectonic mélanges shows that they form during shearing of sediments (e.g. Cowan, 1974; Bosworth and Vollmer, 1981; Fisher and Byrne, 1987; Vollmer and Bosworth, 1984), but their occurrence in protodécollements outboard of the deformation front in subduction zones suggests that they may initiate after very little shear strain (Labaume et al., 1997; Maltman et al., 1993). Scaly fabrics composed of highly polished anastomosing slip surfaces have been reported in the creeping section of the San Andreas at Parkfield (Bradbury et al., 2011), the rupture area of the Tohoku earthquake in the Japan Trench (Fig. 1A; Chester et al., 2013; Kirkpatrick et al., 2015), and at the base of landslides and glaciers (Vannucchi et al., 2003). This raises the possibility that fast and slow slip may be accommodated by distributed shearing across scaly fabrics.

However, little is known about the formation and slip distribution within scaly fabrics. Some scaly fabrics show grain-scale alignment of clay particles, while others are formed by discrete slip surfaces dividing microlithons without strong internal fabrics (Prior and Behrmann, 1990; Carreras et al., 2010). High pore pressure, fluid flow, and volume strain are thought to play a role in scaly fabric formation (Morgan and Karig, 1995; Wallace et al., 2003; 
Takizawa and Ogawa, 1998; Housen et al., 1996). Observations of newly grown clays lining the shear surfaces in the San Andreas Fault Observatory at Depth (SAFOD) drill core suggest that solution and precipitation may also play a role (Schleicher et al., 2010).

Clay deformation experiments are usually performed on disaggregated and reconstituted samples, and the subset of studies which report postshearing microstructure are dominated by localized slip on sharp surfaces, and don't form scaly fabrics (for a review, see Ikari et al. (2011)). The behavior of established networks of anastomosing fabrics undergoing simple and/or pure shear are largely unexplored. To address this issue, we developed an analog experimental approach using oriented anisotropic granular materials to qualitatively describe anastomosing slip distribution geometry. Here we report the observations of patterns of slip distribution and reorganization in the analog system and discuss implications for slip on natural faults.

\section{Experimental methods}

We performed 'sandbox' type shear experiments using lentils packed with an initial vertically-aligned fabric (Fig. 1B and 2D; see supplementary materials for details on grain size, aspect ratio and quantitative measures of alignment). The alignment was achieved by adding the lentils in thin layers and compacting the grains lightly until they align.

Lentils were chosen as they approximate the shape of individual phacoids that commonly comprise scale fabrics while the grain boundaries represent the anastomosing surfaces (Fig. 1). We used a custom-built apparatus which consists of a rectangular box with a plexiglass front, in which a stepper motor 
drives one half of the floor to descend at a controlled rate (plans in Supplement). The lentils are confined horizontally by the four sides of the box, and unconfined at the top. The initial alignment of the lentils created an anastomosing network of inter-grain surfaces sub-parallel to the imposed displacement and normal to the clear viewing panel. We consider this network to be an analog of an established scaly fabric. We recorded high-resolution video during each experiment. The slip rate was varied from $0.4 \mathrm{~mm} / \mathrm{s}$ to $5.0 \mathrm{~mm} / \mathrm{s}$ over a total displacement of $50 \mathrm{~mm}$. For some experiments, we reversed the motion, to examine the effect of gravity on the slip distribution. The time-lapse photographs and movies were analyzed with a Particle Image Velocimetry tool (PIV), PIVlabs (Thielicke and Stamhuis, 2014) (see supplementary materials for PIV parameters). Comparison of lentil motion between frames enabled the identification of individual slip surfaces within the deforming zone, and mapping of the displacement patterns during shear. All experiments were run dry, without any fluids.

\section{Observed behaviors}

After 25 experiments, we observed consistent behaviors regardless of the variations in experimental parameters. Initiation of slip resulted in the near simultaneous development of multiple transient slip surfaces in the lenticular matrix in a V-shaped deformation zone (Fig. 2A-C). The deformation zone was rapidly established within $0.7 \mathrm{~mm}$ of shear box displacement (10\% of average grain diameter; Fig. 2A) and its cross-section area fluctuated by $15 \%$ at most during the experiments (Fig. 2).

Continual rearrangement of slip surface geometries within the zone re- 
sulted in global smooth slip, facilitated by irregular increments of motion by individual lentils and groups of lentils (see Supplementary Material for video). Active slip surfaces were transient, and varied in length from the long dimension of a single lentil, to irregular surfaces that meandered across nearly the entire box of lentils. Reorganization of active slip surfaces occured constantly, with observable changes in slip geometry at every increment measured. We describe three modes by which the slip surfaces through the lentils reorganize during shear (Fig. 3).

The first mode (Fig. 3A) results from the dilation required for lentils to move past one another (Reynolds dilatancy). This dilation transiently increased the normal stress across the shearing surface, discouraging slip between lentils and causing recruitment of neighboring lentils into the deforming zone. Lentils which were aligned horizontally (widest parts touching) support the largest pore spaces between them, but the pores remained smaller than one lentil, and the touching lentils composed a horizontal force chain, resulting in slip around the outside of the aligned lentils. When one or more lentils dropped, breaking the horizontal force chain, the lentils realigned and compacted, and motion migrated on to a narrow slipping surface. Previous workers have shown that this mode of deformation becomes less efficient as grains increase in aspect ratio (Reynolds, 1886; Mead, 1925; Wegner et al., 2014). In the elongate lentils, slip of $\sim 1$ lentil length resulted in compaction and local realignment (Fig. 3A). Due to the simultaneous slip of several parallel surfaces across the deforming zone, dilation in one place was balanced by compaction somewhere else, and there was no significant net change in the width of the deforming zone. 
The second mode, dilatancy with significant rotation, only occured in the downward shear experiments, and thus is facilitated by gravity (Fig. 3B). In this mode, transient large voids formed, supported by groups of lentils which rotate from $\sim 25^{\circ}-180^{\circ}$ around a horizontal axis. Slip ceased across the dilated zone, and migrated to adjacent lentil surfaces (columns 3-5 of Fig. 3B). Recovery occurred by a similar mechanism, in that rotation of lentils with continued shear results in compaction and the establishment of a single or dual slip surfaces. However, this was rarely on the same slip surface as that observed before the dilation event. Sufficient dilatancy to cause catastrophic failure was never achieved (c.f. Moore and Iverson, 2002).

The third mode involved interlocking of a group of lentils, usually of similar aspect ratio as a single lentil, which we call a 'superlentil'. This locking is favored in angular particles (Guo and $\mathrm{Su}, 2007$ ). Superlentils emerged at the intersection of two slipping surfaces, with similar orientation to the edges of the lentils themselves, around a relatively compact region of lentils with little or no interior deformation (Fig. 3C; see Supplementary material for movie). This configuration was destroyed when one of the shear surfaces became sufficiently misoriented with respect to the imposed displacement, typically after slip equivalent to 1-2 lentil lengths.

The modes were observed across the entire tested slip rate range. At the highest slip rate velocities $(5.0 \mathrm{~mm} / \mathrm{s})$, the role of dilatancy became more significant, a relationship that has been noted in experimental studies (Morrow and Byerlee, 1989), and mode 2 reorganizations dominated (Fig. 3B). In all experiments, the overall bulk aligned fabric is continually preserved, but no localized slip persisted, and no principle slip surfaces developed. The slip 
surfaces after reorganization tend to localize wherever the porosity is greatest. With recovery of alignment, all lentil surfaces are equally prone to slip. This effect causes the global behavior of the system to constantly reorganize, and prohibits the persistence of any through-going slip surfaces throughout the entire deforming region. Thus, the natural state of the system is one of transient localization and delocalization.

\section{Implications for scaly fabrics in faults}

Although the lentils we used in our experiments are simple analogs for real scaly clays, the behaviors we observe may be relevant to settings where the anastomosing surfaces are established and strain is distributed through the network. In their model for the development of scaly fabric in partially unconsolidated muds, Moore et al. (1986) propose that the formation of scaly fabric occurs by sequential failure and strain hardening of slip surfaces. The lentils have low friction and cohesion across boundaries, whereas phacoids of scaly clay may adhere to one another, increasing the survival of superlentil clusters. Evidence in nature for this includes comminution along slip surfaces on phacoid faces Vollmer and Bosworth (e.g. 1984) and interphacoid cements such as calcite. This is a possible mechanism for generating phacoids of variable size but similar aspect ratio, as commonly observed in scaly fabrics (Vannucchi et al., 2003; Caine, 1991; Kirkpatrick et al., 2015).

The motion of an individual lentil is on average parallel to the imposed displacement, but in detail, particle paths are complicated by transient locking, reorienting, and lateral shifting during reorganization of the shear networks. Thus, the shear displacement on the surface of lentils is not necessarily 
related to the displacement boundary conditions, but depends on the particle paths of surrounding lentils. The complications in using slickenlines from scaly fabrics to resolve shear sense (Wojtal, 2001) are likely explained by this phenomenon.

While our lentils are rigid, the phacoids in phyllosilicate-rich rock which define natural scaly fabrics have the potential to deform internally during shear (Vollmer and Bosworth, 1984; Caine, 1991; Vannucchi et al., 2003). One consequence is that the Reynolds dilatancy (Fig. 3A) may be less pronounced in natural scaly fabrics, because the clay phacoids may accommodate some of the required deformation by changing shape. As the Reynolds dilatancy is thought to be responsible for reducing pore pressure and increasing effective normal stress during shearing (Rice, 1975; Segall and Rice, 1995), we predict a lesser degree of dilatant strengthening in scaly fabrics than in granular fault materials with rounded, rigid particles.

The deforming zone in our experiments forms a triangular shape, originating at the corner of our apparatus where displacement is imposed on the packed lentils, and broadening toward the surface with boundaries dipping $\geq 75^{\circ}$ (Fig. 2). The wedge is wider on the down-dropped side, likely due to reduction in confinement favoring motion on that side of the 'fault'. While this shape is clearly an artifact created by our experimental geometry, it does display the tendency of the system to distribute strain as broad as geometrically possible, in the absence of cohesion. Natural occurrences of scaly fabrics may reach thicknesses of 10s of meters in subduction thrust faults. Phacoidally cleaved zones may reach thicknesses of 10s of metres to even kms (Vollmer and Bosworth, 1984; Caine, 1991; Vannucchi et al., 2003; 
Rowe et al., 2013), consistent with delocalization as a constitutive behavior (as predicted by Moore and Sample, 1986).

Natural scaly fabrics show evidence of numerous phenomena that might strengthen or weaken individual surfaces (clay growth, Schleicher et al. (2010); plastic internal deformation, Prior and Behrmann (1990); polishing and clay alignment, Labaume et al. (1997); pore pressure transients; Moore and Sample (1986)). In the absence of these processes in our experiments, the grain interfaces representing the scaly fabric have no mechanism for evolving strength aside from local compaction and rotation with respect to the local stress field. Since individual slip surfaces are short, and readily destroyed by the shifting of adjacent grains, we see no evidence that frictional stresses evolve during our experiments. The simultaneous action of sub-parallel shearing surfaces disturbs any transient favorable alignments that form through-going faults. Although patches of grains with the highest porosity are favored to slip, this action rotates grains back into parallelism and encourages compaction. Thus, the delocalized shearing through the network of anastomosing surfaces is self-perpetuating. The three modes of rearrangement we describe in Fig. 3 are all simultaneously active, and local arrangement of lentils controls how deformation will proceed. At the conclusion of each experiment, every lentil interface within the deforming wedge has slipped at least once. The wedgeshaped deforming zone (Fig. 2) represents the integrated distribution of slip over the lifetime of the 'fault', but not due to incremental growth. The wedge represents the deforming width of a distributed shearing system. 


\section{Conclusions}

Our experiments demonstrate that shear in a scaly fabric can be accommodated by multiple simultaneous transient slip surfaces within a deforming region. The deformation region is quickly established with the onset of shear and its geometry and width do not significantly change with ongoing shear. Slip preferentially initiates in regions of high porosity with dilatancy and collapse events playing a significant role in creating short-lived local increases in porosity in the fabric. The fabric retains no 'memory' of individual slip surfaces while retaining its bulk anastomosing character. Once porosity in a region returns to pre-shearing levels, slip is equally likely to occur on recently slipped surfaces as on any other surface between lentils. The behaviors observed in our analog experiments indicate that gradual distributed shearing is facilitated by transient and shifting motions on networks of shears. This behavior is self-perpetuating as due to interactions between parallel shear surfaces that heal transient dilatancy and distort through-going shears.

\section{Acknowledgments}

We thank the McGill Field Rheology Group for thorough and thoughtful suggestions that improved this paper. We thank James Kirkpatrick and Heather Savage for their constructive comments. This work was supported by the Natural Sciences and Engineering Research Council of Canada (NSERC) Undergraduate Student Research Award (USRA) (Tarling) and the R. P. Wares Faculty Scholarship (Rowe). We thank Jonathan Saul Caine and Janos Urai for extremely helpful reviews on an earlier version of this paper. 


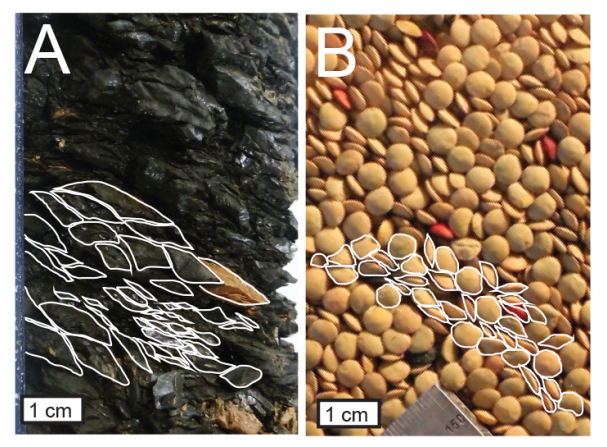

Figure 1: (A) Scaly clays from the plate boundary fault, Japan Trench (Exp 343 Proceedings; Chester et al. (2013)) (B) Analog scaly fabric (Laird lentils) Flattening against transparent wall of box lends to increased percentage of lentils seen in plan view, compared to lentils inside shearing volume. 

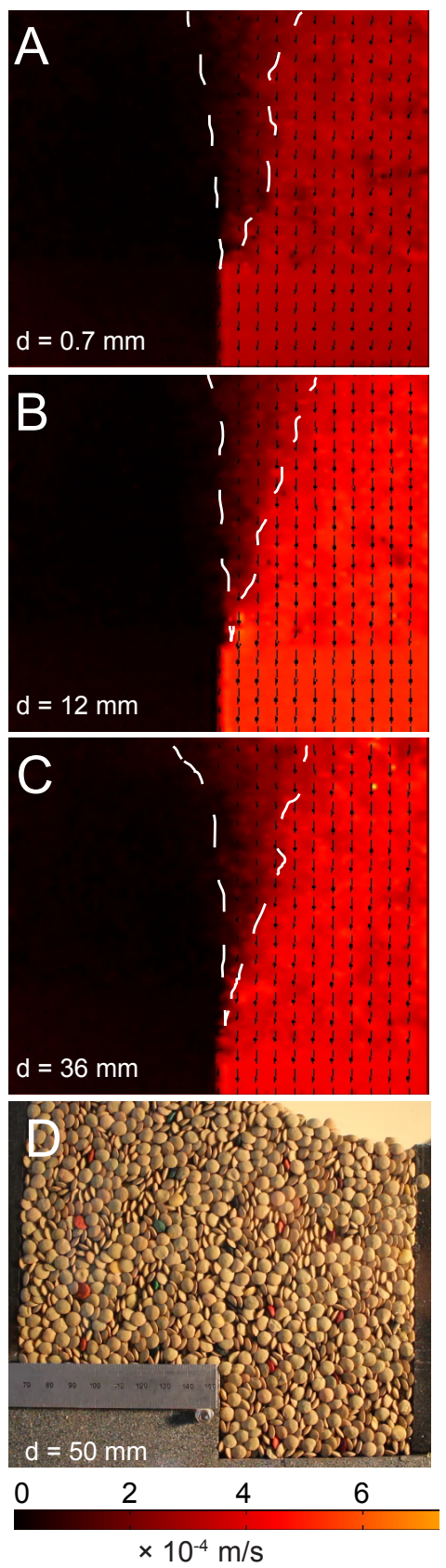

Figure 2: A-C: Velocity maps from PIV analyses at 3 steps of displacement. D: Apparatus after completion of experiment. Total shearing region shown with dashed white line. Deformation region is quickly established and does not evolve significantly throughout experiment. Slip rate of $0.4 \mathrm{~mm} / \mathrm{s}$. 


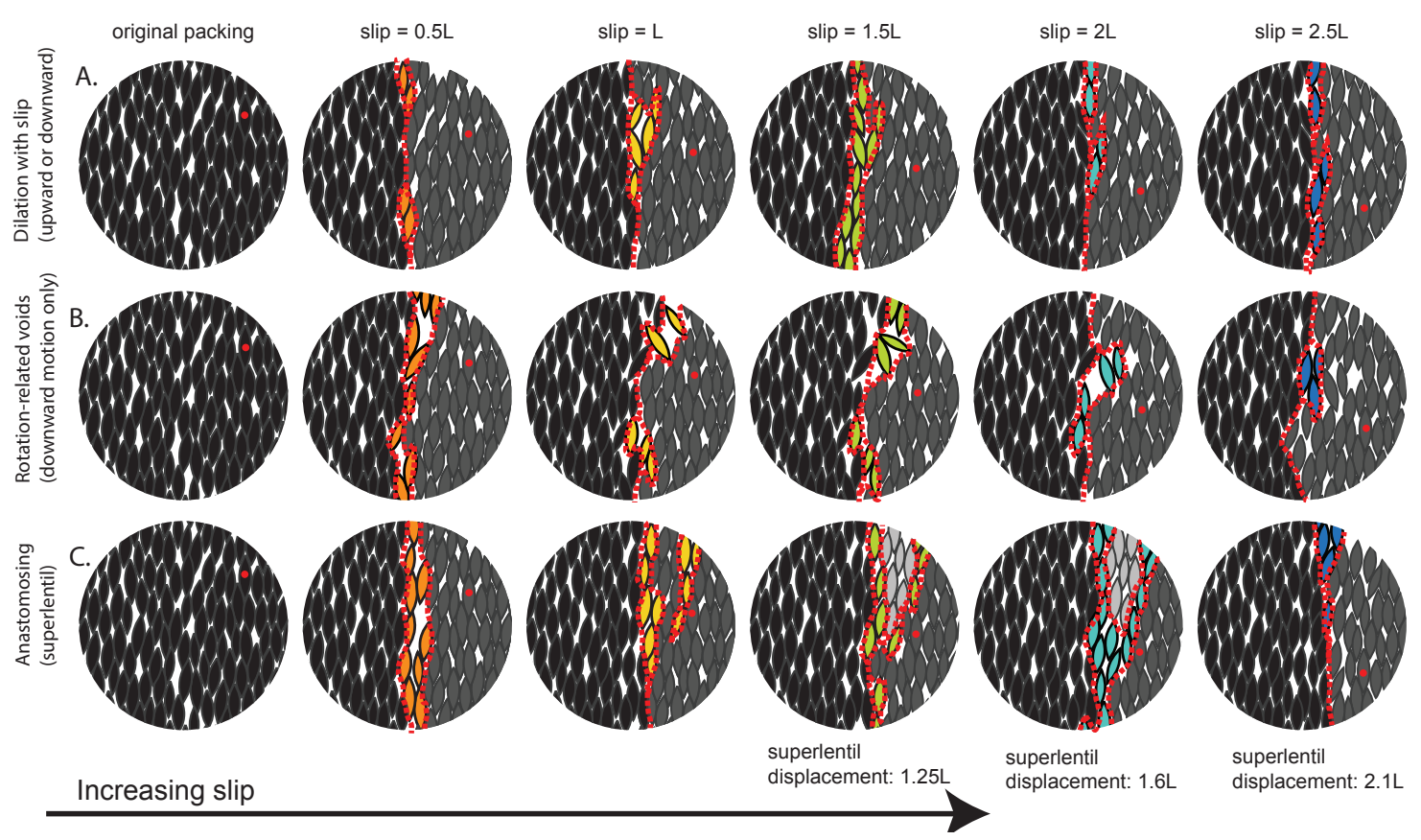

Figure 3: Three modes of shear surface reorganization: Reynolds dilation and recovery (A), by dilation with catastrophic collapse (B), and by 'superlentil' development (C). Length of lentil $=\mathrm{L}$. In all frames, black lentils are stationary, dark gray lentils shift down as a block by one half lentil length in each frame (left to right). The same lentil on the moving side is marked with a red dot in each frame. The lentils which slip and rotate independently between each frame are colored. Shear surfaces are delineated with dashed red lines In (C), light gray lentils are loosely locked together to form a 'super lentil' which slips relative to both black (stationary) and dark gray (slipping at full rate) lentils without internal deformation. 


\section{References}

Bosworth, W., Vollmer, F., 1981. Structures of the medial ordovician flysch of eastern new york: deformation of synorogenic deposits in an overthrust environment. The Journal of Geology, 551-568.

Bradbury, K. K., Evans, J. P., Chester, J. S., Chester, F. M., Kirschner, D. L., 2011. Lithology and internal structure of the San Andreas fault at depth based on characterization of Phase 3 whole-rock core in the San Andreas Fault Observatory at Depth (SAFOD) borehole. Earth and Planetary Science Letters 310, 131-144.

Caine, J. S., 1991. Melange fabrics of the northern appalachians. Master's thesis, SUNY New Paltz.

Carreras, J., Czeck, D. M., Druguet, E., Hudleston, P. J., 2010. Structure and development of an anastomosing network of ductile shear zones. Journal of Structural Geology 32, 656-666.

Chester, F. M., Rowe, C., Ujiie, K., Kirkpatrick, J., Regalla, C., Remitti, F., Moore, J. C., Toy, V., Wolfson-Schwehr, M., Bose, S., Kameda, J., Mori, J. J., Brodsky, E. E., Eguchi, N., Toczko, S., Expedition 343 and 343T Scientists, 2013. Structure and composition of the plate-boundary slip-zone for the 2011 Tohoku-oki earthquake. Science 342, 1208-1211.

Cowan, D. S., 1974. Deformation and metamorphism of the Franciscan subduction zone complex northwest of Pacheco Pass, California. Geological Society of America Bulletin 85, 1623-1634. 
Denis, M., Guiraud, M., Konaté, M., Buoncristiani, J.-F., 2010. Subglacial deformation and water-pressure cycles as a key for understanding ice stream dynamics: evidence from the Late Ordovician succession of the Djado Basin (Niger). International Journal of Earth Sciences 99, 13991425 .

Dilek, Y., Festa, A., Ogawa, Y., Pini, G. A., 2012. Chaos and geodynamics: Mélanges, mélange-forming processes and their significance in the geological record. Tectonophysics 568, 1-6.

Fisher, D., Byrne, T., 1987. Structural evolution of underthrusted sediments, Kodiak Islands, Alaska. Tectonics 6 (6), 775-793.

Guo, P., Su, X., 2007. Shear strength, interparticle locking, and dilatancy of granular materials. Canadian Geotechnical Journal 44 (5), 579-591.

Housen, B. A., Tobin, H. J., Labaume, P., Leitch, E. C., Maltman, A. J., Ocean Drilling Program Leg 156 Shipboard Science Party, 1996. Strain decoupling across the decollement of the Barbados accretionary prism. Geology 24 (2), 127-130.

Ikari, M. J., Marone, C., Saffer, D. M., 2011. On the relation between fault strength and frictional stability. Geology 39 (1), 83-86.

Kirkpatrick, J. D., Rowe, C. D., Ujiie, K., Moore, J. C., Regalla, C., Remitti, F., Toy, V., Wolfson-Schwehr, M., Kameda, J., Bose, S., Chester, F. M., 2015. Structure and lithology of the Japan Trench subduction plate boundary fault. Tectonics 34, 53-69. 
Labaume, P., Maltman, A. J., Bolton, A., Tessier, D., Ogawa, Y., Takizawa, S., 1997. 4. Scaly fabrics in the sheared clays from the decollement zone of the barbados accretionary prism. In: Shipley, T. H., Ogawa, Y., Blum, P., Bahr, J. M. (Eds.), Proceedings of the Ocean Drilling Program, Scientific Results. Vol. 156. Ocean Drilling Program, pp. 59-77.

Larue, D. K., Hudleston, P. J., 1987. Foliated breccias in the active Portuguese Bend Landslide Complex, California: Bearing on melange genesis. The Journal of Geology 95 (3), 407-422.

Maltman, A. J., Byrne, T., Karig, D. E., Lallemant, S., 1993. Deformation at the toe of an active accretionary prism: synopsis of results from ODP Leg 131, Nankai, SW Japan. Journal of Structural Geology 15 (8), 949-964.

Mead, W. J., 1925. The geologic role of dilatancy. The Journal of Geology, 685-698.

Moore, J. C., Roeske, S., Cowan, D. S., Lundberg, N., Gonzales, E., Schoonmaker, J., Lucas, S. E., 1986. Scaly fabrics from deep sea drilling project cores from forearcs. Geological Society of America Memoirs 166, 55-74.

Moore, J. C., Sample, J. C., 1986. Mechanisms of accretion at sedimentdominated subduction zones: consequences for the stratigraphic record and accretionary prism hydrogeology. Memoirs of the Society Geologica Italia 31, 107-118.

Moore, P. L., Iverson, N. R., 2002. Slow episodic shear of granular materials regulated by dilatant strengthening. Geology 30 (9), 843-846. 
Morgan, J. K., Karig, D. E., 1995. Décollement processes at the Nankai accretionary margin, southeast Japan: Propagation, deformation, and dewatering. Journal of Geophysical Research 100 (B8), 15221-15231.

Morrow, C. A., Byerlee, J. D., 1989. Experimental studies of compaction and dilatancy during frictional sliding on faults containing gouge. Journal of Structural Geology 11 (7), 815-825.

Prior, D. J., Behrmann, J. H., 1990. Thrust-related mudstone fabrics from the Barbados forearc: A backscattersd scanning electron microscope study. Journal of Geophysical Research 95 (B6), 9055-9067.

Reynolds, O., 1886. Experiments showing dilatancy, a property of granular material, possibly connected with gravitation. Proceedings of the Royal Institution of Great Britain, with Abstracts of the Discourses Delivered at the Evening Meetings 11, 354-363.

Rice, J. R., 1975. On the stability of dilatant hardening for saturated rock masses. Journal of Geophysical Research 80 (11), 1531-1536.

Rowe, C. D., Moore, J. C., Remitti, F., Party, I. E. T. S., 2013. The thickness of subduction plate boundary faults from the seafloor into the seismogenic zone. Geology 41 (9), 991-994.

Schleicher, A. M., van der Pluijm, B. A., Warr, L. N., 2010. Nanocoatings of clay and creep on the San Andreas fault at Parkfield, California. Geology 38, 667-670, doi: 10.1130/G31091.1.

Segall, P., Rice, J. R., 1995. Dilatancy, compaction, and slip instability of a 
fluid-infiltrated fault. Journal of Geophysical Research 100 (B11), 22,15522,171 .

Takizawa, S., Ogawa, Y., 1998. Dilatant clayey microstructure in the Barbados décollement zone. Journal of Structural Geology 21, 117-122.

Thielicke, W., Stamhuis, E. J., 07 2014. PIVlab - TimeResolved Digital Particle Image Velocimetry Tool for MATLAB. http://dx.doi.org/10.6084/m9.figshare.1092508.

Vannucchi, P., Maltman, A., Bettelli, G., Clennell, B., 2003. On the nature of scaly fabric and scaly clay. Journal of Structural Geology 25, 673-688.

Vollmer, F., Bosworth, W., 1984. Formation of melange in a foreland basin overthrust setting: Example from the taconic orogen. Geological Society of America Special Papers 198, 53-70.

Wallace, G., Moore, J. C., DiLeonardo, C. G., 2003. Controls on localization and densification of a modern decollement: Northern Barbados accretionary prism. Geological Society of America Bulletin 115 (3), 288-297.

Wegner, S., Stannarius, R., Boese, A., Rose, G., Szabó, B., Somfai, E., Börzsönyi, T., 2014. Effects of grain shape on packing and dilatancy of sheared granular materials. Soft Matter 10, 5157-5167.

Wojtal, S. F., 2001. The nature and origin of asymmetric arrays of shear surfaces in fault zones. Geological Society of London, Special Publications 186, 171-193. 